\title{
A Cytopathological Study of Malignant Thyroid Lesions and Its Implications in A Referral Center
}

\author{
Shifa Syed Ibrahim*, Sharmila Thilagavathy Narayanan and Meenakumari Gopalakrishnan \\ Department of Pathology, Madurai Medical College, Madurai. India
}

\begin{abstract}
Background: Fine needle aspiration [FNA] is the well-established diagnostic modality. It has a positive predictive value of $99 \%$ in diagnosing malignant thyroid lesions. The incidence of various thyroid malignancies in our department was evaluated using FNA and they were compared to those available in the literature.

Methods: During our study period, cases those were referred to our lab for FNAC thyroid were retrieved from the records. From that, malignant cases reported during our study period were enumerated and reexamined. The prevalence of malignant cases, its age and sex incidence was calculated. Increase in the incidence of undifferentiated thyroid carcinoma cases in our setup was recognized and our experience was compared with those available in the literatures.

Result: During our study period, 339 thyroid cases were reported. The incidence of papillary carcinoma was $26.3 \%$ and anaplastic carcinoma was 58\% in our study. Peak age incidence was around 50-60 years. Female predominance was noted in all age groups except in the 50-60 year category where male predominated. When the tumor was staged based on TNM classification, anaplastic carcinoma presented with a higher stage.
\end{abstract}

Conclusion: Thyroid FNAC has a high predictive value in the diagnosis of malignancies. The incidence of undifferentiated carcinoma was higher in our setup. The reason for the increase in the incidence needs further evaluation.

\section{Keywords: Papillary, Insular, Anaplastic, Medullary.}

\section{Introduction}

Benign thyroid nodules are commonly encountered in a fine needle aspiration [FNA] clinic. The incidence of malignant thyroid nodule is $5 \%{ }^{[1]}$. The positive predictive value of FNA in diagnosing malignant thyroid lesion is $99 \%{ }^{[2]}$. Among the malignant tumors of the thyroid papillary carcinoma of thyroid [PTC] is the most common constituting around $80 \%$ of all the thyroid malignancy ${ }^{[3]}$. Poorly differentiated thyroid carcinomas [PDTC] accounts for $4 \%$ to $7 \%$ of thyroid carcinomas, undifferentiated (or anaplastic) carcinoma of the thyroid [UTC] represents less than $5 \%$ of malignant thyroid tumors, medullary thyroid carcinoma [MTC] accounts for $5 \%$ to $10 \%$ of all thyroid carcinomas, squamous cell carcinoma [SQC] of the thyroid accounts for $1 \%$ or less of thyroid cancers and metastatic tumors to the thyroid are constitute $0.1 \%$ to $0.3 \%$ of thyroid aspirates $^{[4,5]}$. Our study was done to calculate the incidence of various malignant tumor in our setup and to compare it with the literature reports.

\section{Materials and Methods}

During our study period for seven months FNA cases that were referred to us for thyroid lesions were retrieved from the records. As both FNA procedure and the interpretation were carried out by the pathologist the accuracy of our diagnosis was more ${ }^{[6]}$. Age, sex, clinical details including thyroid profile, duration of the lesion, family history of thyroid cancer, previous head and neck irradiation, rapid growth, hardness or adherence of the lump to surrounding structures and the presence of associated lymphadenopathy and clinical examination of the thyroid including size were retrieved from the records. Age and sex incidence were calculated. The size [based on ultrasound findings] based split of malignant lesions was done to evaluate the stage at which each thyroid carcinoma presented in our study. The slides were reexamined by three cytopathologists as recommended by Bethesda reporting of thyroid cytology [TBSRTC] and lesions were categorized according to Bethesda recommendations. Malignant lesions were categorized into type based on the morphology. Because malignancy in follicular neoplasm cannot be made on cytology, these lesions were not included in our study. The incidence of various thyroid malignancies was calculated. These findings were compared with the available literature reports. As our study used fine needle aspiration as a single diagnostic modality as it do have a higher sensitivity and specificity, neither histopathological correlation nor follow up was done. 


\section{Result}

During our study period for seven months from January 2016 to July 2016, 1999 cases were referred to our FNA clinic for cytopathological diagnosis. 339 cases were referred for thyroid FNA [Table 1]. Those cases were reported based on Bethesda recommendations.

Eighty five percentages of the thyroid cases were benign. $1.8 \%$ of the cases were diagnosed as follicular neoplasms and malignant lesion constitute around $5.6 \%$ in our study. Among the malignant thyroid lesions, papillary carcinomas constitute about $26.3 \%$ and anaplastic carcinoma constitutes about 58\%. PTC was seen below 20 years and rest of the tumors peaked around 50-60 years. The incidence of malignant neoplasm in 50-60 years was $36.8 \%$ [Table 2].

When sex incidence was calculated, in the age group 50-60 years male predominance was noted [M: F: 2.5:1]. In all other age groups female predominance was noted [Table 2]. When stage of the tumor was compared with the type of tumor, higher stage was noticed in anaplastic carcinoma [Table 1].

Table 1: Stratification of various thyroid lesions we had encountered in our study based on Bethesda recommendation.

\begin{tabular}{|c|c|c|c|c|c|c|c|c|c|c|c|c|c|c|c|c|c|}
\hline \multirow{2}{*}{$\begin{array}{c}\text { Non } \\
\text { diagnostic or } \\
\text { Unsatisfactory }\end{array}$} & \multicolumn{2}{|c|}{ Benign } & \multirow{2}{*}{$\begin{array}{l}\text { Follicular } \\
\text { Neoplasm }\end{array}$} & \multirow{2}{*}{$\begin{array}{l}\begin{array}{c}\text { Suspicious } \\
\text { for } \\
\text { Malignancy }\end{array}\end{array}$} & \multicolumn{12}{|c|}{ Malignant } & \multirow[b]{2}{*}{ Total } \\
\hline & $\begin{array}{l}\text { Benign } \\
\text { follicular } \\
\text { nodule }\end{array}$ & $\begin{array}{c}\text { Lymphocytic } \\
\text { (Hashimoto) } \\
\text { thyroiditis }\end{array}$ & & & \multicolumn{4}{|c|}{$\begin{array}{c}\text { Papillary thyroid } \\
\text { carcinoma }\end{array}$} & \multicolumn{4}{|c|}{$\begin{array}{c}\text { Medullary thyroid } \\
\text { carcinoma }\end{array}$} & \multicolumn{4}{|c|}{$\begin{array}{c}\text { Undifferentiated } \\
\text { (anaplastic) } \\
\text { carcinoma }\end{array}$} & \\
\hline \multirow{2}{*}{10} & \multirow{2}{*}{268} & \multirow{2}{*}{36} & \multirow{2}{*}{6} & \multirow{2}{*}{3} & $\mathrm{~T} 1$ & $\mathrm{~T} 2$ & T3 & T4 & T1 & T2 & T3 & $\mathrm{T} 4$ & T1 & $\mathrm{T} 2$ & T3 & $\mathrm{T} 4$ & \multirow{2}{*}{339} \\
\hline & & & & & 1 & 2 & 1 & - & - & - & 1 & - & - & - & - & 10 & \\
\hline
\end{tabular}

Table 2: Age and sex wise stratification of the malignant thyroid lesions.

\begin{tabular}{|c|c|c|c|c|c|c|c|c|c|c|}
\hline & \multirow{2}{*}{$\begin{array}{c}<20 \text { Years } \\
\text { PTC }\end{array}$} & \multirow{2}{*}{$\begin{array}{c}\text { 21-30 years } \\
\text { PTC }\end{array}$} & \multirow{2}{*}{$\begin{array}{c}\text { 31-40 years } \\
\text { UTC }\end{array}$} & \multirow{2}{*}{$\begin{array}{c}\text { 41-50 years } \\
\text { SOM }\end{array}$} & \multicolumn{4}{|c|}{$51-60$ years } & \multirow{2}{*}{$\begin{array}{c}61-70 \\
\text { years } \\
\text { UTC }\end{array}$} & \multirow{2}{*}{$\begin{array}{c}\begin{array}{c}>1 \\
\text { years }\end{array} \\
\text { UTC }\end{array}$} \\
\hline & & & & & PTC & MTC & UTC & SOM & & \\
\hline Male & - & - & 1 & - & 1 & 1 & 3 & 2 & 1 & 1 \\
\hline Female & 2 & 1 & 2 & 1 & - & - & 1 & 1 & 2 & 1 \\
\hline
\end{tabular}

PTC-Papillary carcinoma thyroid, MTC-Medullary carcinoma thyroid, UTC-Undifferentiated carcinoma thyroid, SOM-Suspicious of malignancy.

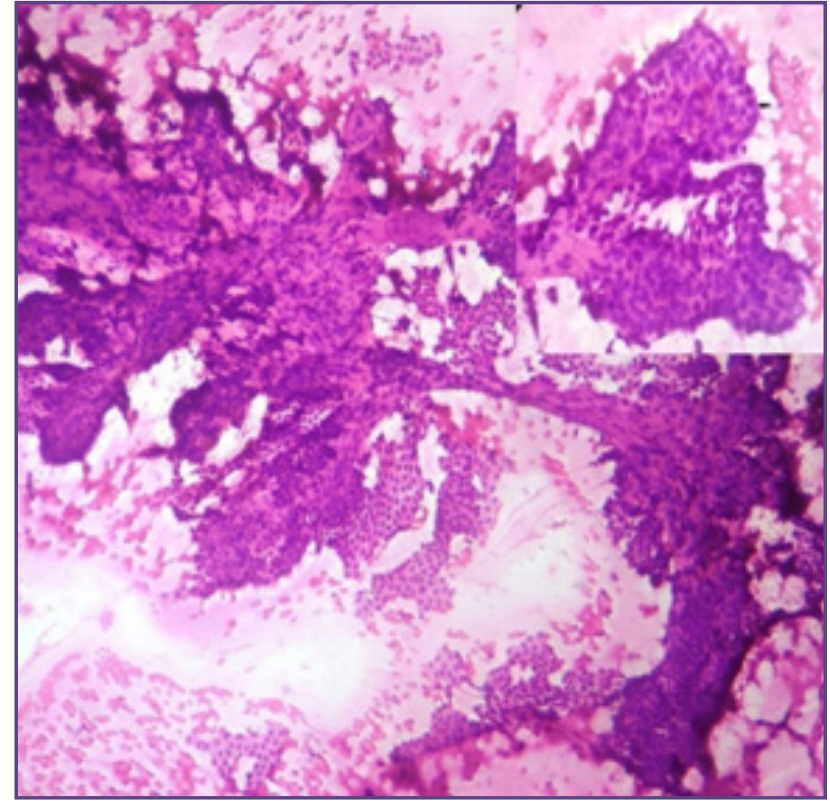

Fig. 1: A: Show oval cells arranged in papillary pattern with anatomical bordering [Black arrow in the inset picture, H\&E, 4x] - Papillary carcinoma thyroid.

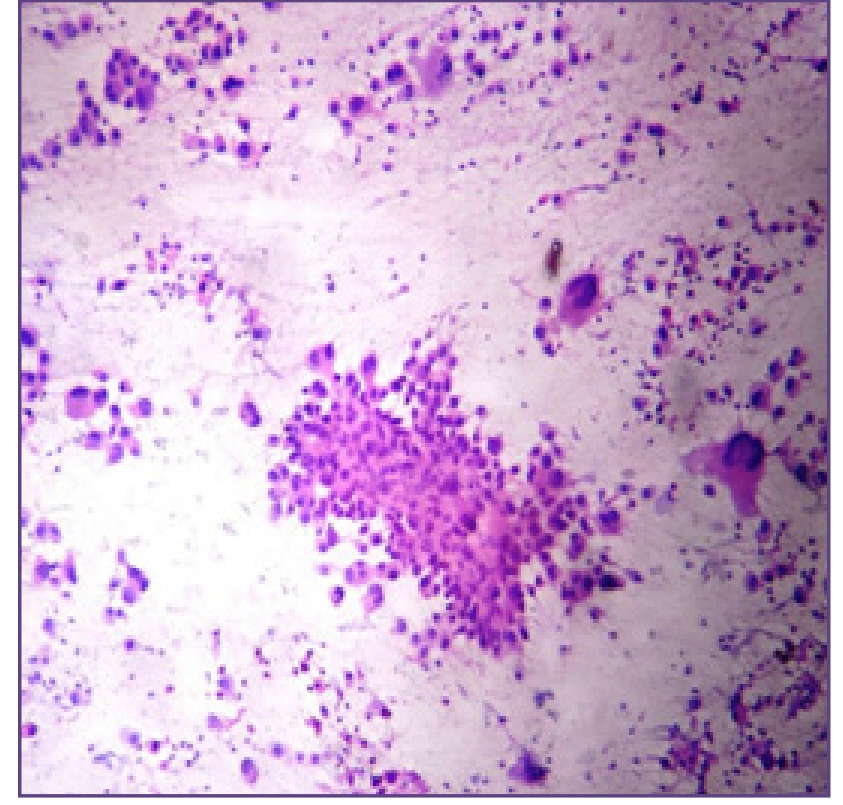

Fig. 2: Show pleomorphic tumor cells arranged in sheets and neutrophils are seen in the background [H\&E, 10x] Undifferentiated carcinoma thyroid. 


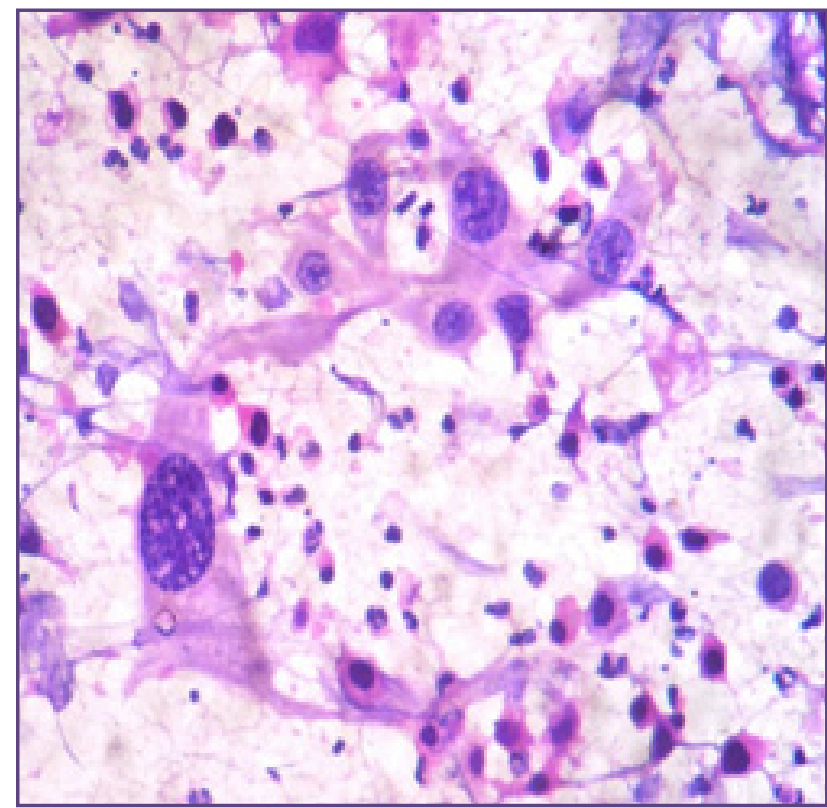

Fig. 3: Show rhabdoid tumor cells arranged in sheets and scattered individually [H\&E, 10x] - Undifferentiated carcinoma thyroid.

\section{Discussion}

Thyroid malignancy is commonest among endocrine tumors. Annual incidence ranges from 1.0 to 2.9 cases per 100,000 men and 3.4 to 9.1 cases per 100,000 women [7]. Thyroid FNA is a rapid, safe, cost-effective modality to diagnose thyroid lesions ${ }^{[8]}$. Cytology has a sensitivity and specificity of up to $94 \%$ and $98 \%$ respectively for the diagnosis of malignant lesions ${ }^{[9]}$. TBSRTC recommends six diagnostic categories which includes - Non diagnostic, benign, atypia of undetermined significance or follicular lesion of undetermined significance, follicular neoplasm or suspicious for a follicular neoplasm, suspicious for malignancy and malignant. Malignancy is more common in solitary nodule and the prevalence of malignancy in solitary cold nodules ranges from $10 \%$ to $44.7 \%{ }^{[10]}$. Malignant thyroid tumors are broadly divided into well differentiated- PTC and follicular carcinoma, poorly differentiated- insular carcinoma and undifferentiatedanaplastic carcinoma.

Papillary carcinoma is the most common malignancy among the thyroid carcinoma. It arises secondary to head and neck radiation and it is associated with BRAF, RAS mutation and RET/PTC rearrangements ${ }^{[11]}$.There is a female preponderance with female to male ratio $4: 1$ and seen in all ages ${ }^{[12]}$. In our study female: male was 3:1 in concordance with Schlumberger M's study [12]. The incidence of PTC peaks around 43+_ 12 years ${ }^{[13]}$. In contrast, the peak age group in our study was 16 years.

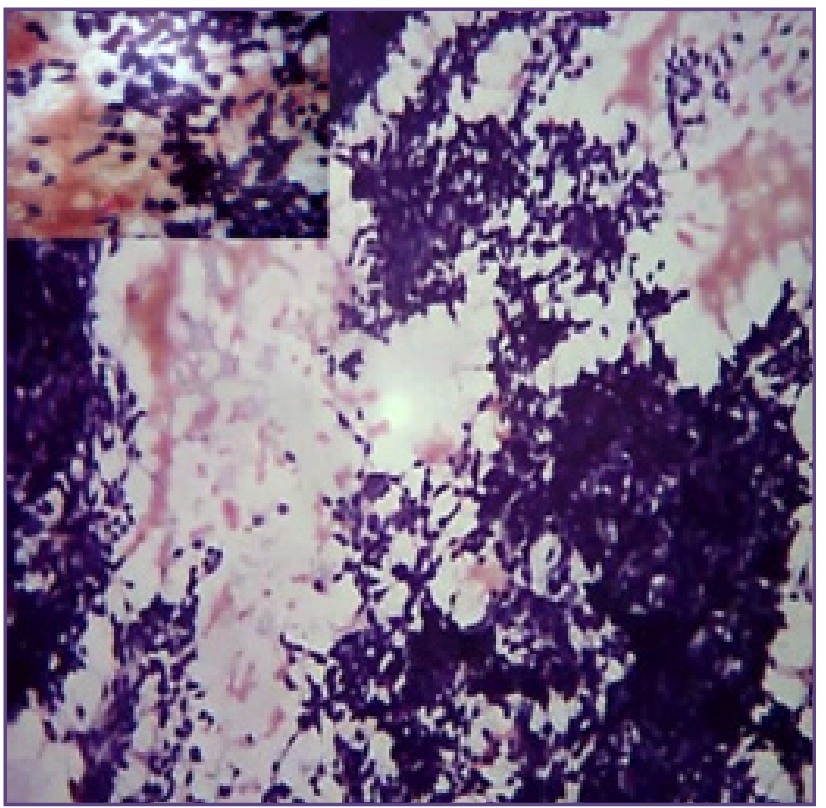

Fig. 4: Show scattered and monolayered sheets of oval to spindle tumor cells in a hemorrhagic background [H\&E, 10x]. Inset shows tumor cells exhibiting dispersed chromatin [H\&E, 40x] - Medullary carcinoma Thyroid.

Pediatric PTCs and PTCs that occur in young adults have some unique features. They are usually larger in size, metastasize early and often present with cervical metastasis ${ }^{[14]}$. These tumors show high expression of sodium-iodide transporter [NIS]. This NIS expression results in increased response to radio iodine therapy resulting in better prognosis ${ }^{[15]}$. The incidence of papillary carcinoma in Sinna E.A and Ezzat N's study was $72.4 \%$, whereas in our study the incidence of PTC was $26.3 \%{ }^{[16]}$.

Grossly, the tumor is solid grey white and cystic changes are seen in $10 \%$ of the cases. Multicentricity and occult tumors less than one centimeter in size are also common in PTC. Histologically, PTC is identified by its nuclear features including, enlarged oval irregular nucleus, overlapping and crowding of the nucleus, grooves, intracytoplasmic inclusions and Orphan Annie nucleus. Nuclear cytoskeletal abnormality leads on deformable nucleus hence the irregular contour, grooves and pseudo inclusions seen in the nucleus ${ }^{[17]}$. Cytologically, PTC shows all the nuclear features except nuclear clearing. Instead the nucleus show dispersed chromatin pattern. Anatomical bordering, nuclear grooves, nuclear overlapping and crowding, intranuclear inclusion and dispersed chromatin are diagnostic of PTC in the cytological smears. All the features should be there to diagnose a PTC [Fig 1]. IHC markers that are specific for PTC includes HBME-1 membranous positivity, cytoplasmic CK19 positivity, CD44, p63 and galectin 3. 
Insular carcinoma is seen in elderly age group with a female predominance. Grossly, tumors are necrotic and have an invasive margin. Histologically, the tumor cells are small arranged in an insular pattern with foci of necrosis. Cytologically, the cells are smaller, with dispersed chromatin, convoluted nuclei, increased mitotic figures [more than $3 / 10 \mathrm{hpf}$ ] in a necrotic background ${ }^{[18]}$. Immunohistochemical markers that are positive include TTF-1, thyroglobulin and synaptophysin. Insular carcinoma was not encountered by us during our study period.

Undifferentiated carcinoma [anaplastic carcinoma] [UTC] constitutes around $17.2 \%$ of all the thyroid malignancies ${ }^{[14]}$. In all other studies the incidence were $<5 \%$ of all the thyroid malignancies ${ }^{[19,20]}$. In contrast, in our study group the incidence was 58\% which was higher than all the study groups seen in the literatures. It is a tumor of elderly females secondary to nodular goiter, FA [Follicular adenoma], FTC [Follicular carcinoma thyroid] and PTC ${ }^{[21]}$. In our study male: female was 1.2:1 in contrast to LiVolsi V A, et al's study [19]. Two cases in our study presented with features of UTC secondary to PTC. It was invasive at presentation and it was associated with both local and distal metastasis. Extra thyroidal extension in UTC tumors was seen in 91\% of our cases [Table 3]. Histologically, this tumor shows both malignant epithelial and spindle cell morphology. Increased mitotic figures and areas of necrosis were also noted. Cytologically, the tumor exhibits malignant spindle component with neutrophilic infiltrates, epithelioid [Fig 2] or rhabdoid [Fig 3] morphologies. This tumor is positive for cytokeratin and PAX8. P53 mutation, RET and RAS mutations are observed in UTC.

Medullary carcinoma thyroid constitutes around 5-10\% of all the thyroid neoplasm ${ }^{[16,22]}$. Likewise in our study too the incidence of MTC was $5.3 \%$. It is associated with RET and RAS mutations. The cell of origin is the parafollicular C cells. It is sporadic or familial. Familial MTC may be isolated familial disease or associated with multiple neuroendocrine syndromes [MEN 2A \&2B]. Sporadic cases show female predominance and familial cases show equal sex distribution. In our study a single case was reported in a male. Histologically, the tumor cells are polygonal or spindle arranged in sheets separated by a fibrovascular septa. The tumor cells show dehiscence and nucleus show stippled chromatin and amyloid is seen in $80-85 \%$ of the cases. The sensitivity of FNAC in detecting MTC is higher than PTC ${ }^{[23]}$. Cytologically, polygonal or spindle shaped cells are arranged individually or form loose monolayer sheets [Fig 4]. Amyloid is also seen. Tumor cells are positive for $\mathrm{CK}$, chromogranin, CEA, calcitonin and TTF-1.
Thyroid malignancies contribute about $1.5-3 \%$ of all carcinomas in children and adolescent group ${ }^{[24]}$. In our study group, PTC was seen predominantly in younger age groups less than twenty years of age constituting $10.5 \%$ of all the thyroid malignancies. Family history of thyroid malignancies and irradiation are considered to be the risk factors associated with thyroid malignancies in young adults. The increased incidence of PTC in young adults in our study group needs further evaluation.

The incidence of UTC was much higher than all the study groups. The reason for increased incidence of UTC in our study group may be because of the following reasons:

UTC might have developed from undiagnosed PTC which was seen predominantly in younger age groups in our study. May be more studies related to the genetic instability associated with PTC might give us a clue.

UTC might have arisen in the background of some unknown gene mutations prevalent in our area which needs further evaluation.

\section{Conclusion}

FNAC is the cheapest available diagnostic tool in classifying a thyroid nodule. There was a female predominance in our study group. The incidence of UTC is $58 \%$ in our study group which needs further analysis.

\section{Reference}

1. Mortensen JD, Woolner LB, Bennett WA. Gross and microscopic findings in clinically normal thyroid glands. J Clin Endocrinol Metab. 1955;15:1270-1280.

2. Jo VY, Stelow EB, Dustin SM, Hanley KZ. Malignancy risk for fine-needle aspiration of thyroid lesions according to the Bethesda System for Reporting Thyroid Cytopathology. Am J Clin Pathol 2010; 134(3):450-6.

3. Rosai J, Carcangiu ML, DeLellis RA. Tumors of the thyroid gland. Atlas of Tumor PathologyWashington, DC: Armed Forces Institute of Pathology; 1992 Fascicle 5, 3rd series.

4. DeLellis RA, Lloyd RV, Heitz PU, Eng C, eds. World Health Organization Classification of Tumours. Pathology and Genetics of Tumours of Endocrine Organs. Lyon, France: IARC Press; 2004:49-134.

5. Schmid KW, Hittmair A, Ofner C, Totsch M, Ladurner D. Metastatic tumors in fine needle aspiration biopsy of the thyroid. Acta Cytol. 1991;35:722-724.

6. Sangalli G, Serio G, Zampatti C, Bellotti M, Lomuscio G. Fine needle aspiration cytology of the thyroid: a comparison of 5469 cytological and final histological diagnoses. Cytopathology 2006; 17: 245-50.

7. Chan JK. Tumors of the thyroid and parathyroid glands. In: Fletcher CDM. Diagnostic histopathology of tumors. 4th eds, Saunders, Philadelphia, Churchill Livingstone; 2013. 1177-1289.

eISSN: 2349-6983; pISSN: 2394-6466 
8. Olson MT, Clark DP, Erozan YS, Ali SZ. Spectrum of Risk of Malignancy in Subcategories of 'Atypia of Undetermined Significance'. Acta Cytol 2011;55(6):518-25.

9. Yang J, Schnadiq V, Logrono R, Wasseman PG. Fineneedle aspiration of thyroid nodules: a study of 4703 patients with histological and clinical correlations. Cancer 2007;111:306-15

10. Ashcroft MW, van Herle AJ. Management of thyroid nodules. I. Head, Neck Surg 1981;3:216-30

11. Henderson YC, Shellenberger TD, Williams MD, El-Naggar AK, Fredrick MJ, Cieply KM, Clayman GL. High rate of BRAF and RET/PTC dual mutations associated with recurrent papillary thyroid carcinoma. Clin Cancer Res 2009;15:485-91.

12. Schlumberger M J Papillary and follicular thyroid carcinoma. N Engl J Med 1998; 338: 297-306

13. Huang FJ, Fang WY, Ye L, Zhang XF, Shen LY, Han R.L et al. BRAF mutation correlates with recurrent papillary thyroid carcinoma in Chinese patients. Curr Oncol, 2014; 21(6): e740-747.

14. Pasieka JL, Thompson NW, McLeod MK, Burney RE, Macha $\mathrm{M}$, Reeve TS. The incidence of bilateral well differentiated thyroid cancer found at completion thyroidectomy, World Journal of Surgery1992:16(4): 711-716.

15. Patel A, Jhiang S, Dogra S, Terrell R, Powers PA, Fenton $\mathrm{C}$, et al. Differentiated thyroid carcinoma that express sodium-iodide symporter have a lower risk of recurrence for children and adolescents. Pediatric Research, 2002: 52( 5); 737-744.
16. Sinna EA, Ezzat N. Diagnostic accuracy of fine needle aspiration cytology in thyroid lesions. Journal of the Egyptian National Cancer Institute 2012; 24: 63-70.

17. Papotti M, Manazza AD, Chiarle R, Bussolati G. Confocal microscope analysis and tridimensional reconstruction of papillary thyroid carcinoma nuclei. Virchows Arch. 2004;444(4):350-355.

18. Volante M, Collini P, Nikiforov YE, Sakamoto A, Kakudo $\mathrm{K}$, Katoh $\mathrm{R}$ et al. Poorly differentiated thyroid carcinoma: the Turin proposal for the use of uniform diagnostic criteria and an algorithmic diagnostic approach.Am J Surg Pathol 2007;31:1256-64.

19. Nel C J, van Heerden J A, Goellner J R, Gharib H, McConahey WM, Taylor WF, et al. Anaplastic carcinoma of the thyroid: a clinicopathologic study of 82 cases. Mayo Clin Proc 1985:60: 51-58

20. Tan R K, Finley R K III, Driscoll D, Bakamjian V, Hicks WL, Jr., Shedd DP. Anaplastic carcinoma of the thyroid: a 24-year experience. Head Neck 1995:17:41-47

21. LiVolsi VA, Brooks JJ, Arendash-Durand B. Anaplastic thyroid tumors. Immunohistology. Am J Clin Pathol 1987:87:434-442

22. Moo-Young TA, Traugott AL, Moley JF. Sporadic and familial medullary thyroid carcinoma: state of the art. Surg Clin North Am 2009;89:1193-204.

23. Papaparaskeva K, Nagel H, Droese M. Cytologic diagnosis of medullary carcinoma of the thyroid gland. Diagn Cytopathol 2000; 22: 351-358.

24. Greenlee R T, Hill-Harmon M B, Murray T, Thun M. Cancer statistics, 2001 Cancer Journal for Clinicians 2001: 51(1):15-36.

*Corresponding author:

Dr. S. Shifa, Department of Pathology, Madurai Medical College, Madurai.

Phone: +91 9486669274

Email: shifafrin@gmail.com

Date of Submission : 03.09.2016

Date of Acceptance : 30.12.2016

Financial or other Competing Interests: None.
Date of Publication : 02.04.2017 